\title{
Damage and partitioned mortality of teleosts discarded from two Australian penaeid fishing gears
}

\author{
Sebastian S. Uhlmann ${ }^{1, *}$, Matt K. Broadhurst ${ }^{2}$ \\ ${ }^{1}$ School of Environmental Sciences and Natural Resources Management, University of New England, \\ National Marine Science Centre, PO Box J321, Coffs Harbour, New South Wales 2450, Australia \\ ${ }^{2}$ New South Wales (NSW) Department of Primary Industries, Fisheries Conservation Technology Unit, PO Box J321, \\ Coffs Harbour, New South Wales 2450, Australia
}

\begin{abstract}
Six field experiments were performed to (1) quantify the scale loss and partitioned (immediate and short-term) mortality of key teleosts discarded from a penaeid seiner and trawler operating in 2 estuaries in southeastern Australia, and (2) assess the utility of modified operational and/or onboard handling procedures for maximising survival. For both gears, several non-target species were caught, handled and discarded according to 2 general categories of treatment ('mild' and 'extreme') representing the plausible limits of severity of commercial operations. The mild treatments involved the shortest conventional deployments of the gears followed by the immediate sorting of catches in water-filled trays, while the extreme treatments comprised the longest conventional deployments and sorting in dry trays. Discards were examined for immediate mortalities and scale loss before sorting onboard, while live individuals of key species, along with appropriate numbers of controls, were released into sea cages and monitored for mortalities up to $5 \mathrm{~d}$. For both gears, there was a trend of higher percentages of immediate mortalities in the extreme treatments, and more scale loss from dead than live seined and trawled silver biddy Gerres subfasciatus, seined tarwhine Rhabdosargus sarba and trawled yellowfin bream Acanthopagrus australis. Despite considerable interspecific variabilities, few intraspecific differences were detected between treatments for the short-term mortalities of live discards; however, for all species, these deaths were greater than those incurred by the controls (most of which survived). The partitioned mortality estimates were combined to provide a range of total mortalities for seined (95.97 and 99.07\%, respectively) and trawled (71.74 and $97.64 \%$ ) G. subfasciatus, seined R. sarba (23.95 and 100\%) and trawled southern herring Herklotsichthys castelnaui (100\%) and A. australis (3.40 and 35.01\%). Because most deaths occurred irrespective of onboard handling procedures, we conclude that simply reducing the duration of gear deployments would provide a first step toward mitigating discard mortality in these fisheries.
\end{abstract}

KEY WORDS: Discards $\cdot$ Partitioned mortality $\cdot$ Penaeid fisheries $\cdot$ Catch volume $\cdot$ Unaccounted fishing mortality

Resale or republication not permitted without written consent of the publisher

\section{INTRODUCTION}

In recent decades, the capture and discarding of unwanted organisms (termed 'bycatch') during commercial fishing has attracted global concern, primarily because of the potential for large unaccounted fishing mortalities and subsequent negative cascading effects on the marine environment (Blaber et al. 2000, Pauly et al. 2002). Owing to their poor selectivity and often highly disproportional ratios of bycatches-to-targeted catches, penaeid (prawn or shrimp) fisheries, especially those involving active gears, have received the most attention (Andrew \& Pepperell 1992, Kelleher 2005), which has resulted in numerous attempts at mitigation strategies (Broadhurst 2000).

Apart from temporal and spatial closures to fishing, the simplest ways of addressing the issue of bycatch in most penaeid fisheries have involved modifications to 
(1) gears to improve species and/or size selection (for a review see Broadhurst 2000) and, less commonly, (2) operational and/or post-capture handling procedures that reduce the mortality of discards (Dunning et al. 1989, Macbeth et al. 2006). Both of these strategies inherently require that the majority of unwanted individuals interacting with a particular fishing gear, and then either escaping during fishing (1 above) or being caught and discarded ( 2 above), actually survive the process. Reviews of the few studies that have tested this assumption acknowledge that the mortalities of such 'escapees' or 'discards' are determined by a range of biological (e.g. species, physiology, size and catch volume and composition), technical (e.g. gear design, deployment duration and speed) and environmental (e.g. temperature, hypoxia, sea state and availability of light) factors (Davis 2002, Broadhurst et al. 2006b). Further, owing to the cumulative negative effects of catch mechanisms involving the above factors on the health of an organism, in many cases, the mortality of discards is considerably greater than that of escapees (Broadhurst et al. 2006b). Recognition of this trend is reflected in the greater majority of attempts at addressing the issue of bycatch in penaeid fisheries using the first strategy outlined above.

However, providing that there are no dominant biological, technical or environmental factors that preclude the survival of key individuals of bycatch discarded from active penaeid gears, simple changes to operational and/or post-capture handling procedures ( 2 above) may have some utility in reducing unwanted mortalities, especially in those gears where selective modifications are either not considered to be sufficiently effective, or have not been developed. Determining the benefits of pursuing this strategy in a particular fishery requires adequate species-specific information on discard mortalities during the full range of influencing factors, and general estimates of what might be achievable under conventional conditions. For example, there is little point in examining changes to post-capture handling procedures if the actual fishing mechanism results in $100 \%$ mortality. As a starting point, categories of 'mild' and 'extreme' treatments within a particular fishing operation need to be identified. In the case of active gears, factors such as gear deployment duration, catch volume and hypoxia have dominant and cumulative effects on the discard mortalities of most species (Davis 2002, Broadhurst et al. 2006b). Quantifying the range of effects that these sorts of factors have on discard mortalities during controlled experiments can therefore provide important information for future attempts at mitigation within a particular fishery.

In this study, we sought to use the above approach to estimate and partition the discard mortalities of key teleosts from 2 towed gears (seines and otter trawls) used to target penaeids (school Metapenaeus macleayi, eastern king Penaeus plebejus and greasyback prawns $M$. bennettae) in estuaries of $\mathrm{New}$ South Wales (NSW), Australia. As in most penaeid fisheries worldwide, in addition to the targeted prawns, NSW estuarine seines and trawls catch a diverse assemblage of small, unwanted organisms, including juveniles of economically important teleosts, such as yellowfin bream Acanthopagrus australis, tarwhine Rhabdosargus sarba and silver biddy Gerres subfasciatus (Liggins \& Kennelly 1996, Liggins et al. 1996, Gray 2001). Concerns over the bycatch and mortality of these and other species (especially those caught by trawlers) have resulted in the development and legislation of modifications to improve selectivity, including the Nordmøre-grid and squaremesh codends (e.g. Broadhurst \& Kennelly 1996). These modifications significantly reduced the total bycatch weights and unwanted fishing mortalities of several key species (including those above) by between about 45 and $90 \%$ (Broadhurst \& Kennelly 1995, 1996, Broadhurst et al. 1996).

While the legislation of modifications to seines and trawls throughout NSW estuaries have mitigated their perceived negative impacts, none of the gears is $100 \%$ selective for the target catches, so for all fisheries there remains at least some discarding. Improvements in operating procedures and/or postcapture handling methods (i.e. strategy 2 above) may provide a simple option for further mitigating unwanted fishing mortalities, particularly since many of the environmental and technical factors known to influence the fate of discards appear to be fairly mild for estuarine fisheries. For example, both gears are deployed from small boats $(<10 \mathrm{~m})$ for short periods $(<1 \mathrm{~h})$ in shallow areas (typically $<5 \mathrm{~m}$ ) and have low catch volumes (typically $<15 \mathrm{~kg} \mathrm{~h}^{-1}$; e.g. Liggins \& Kennelly 1996, Liggins et al. 1996, Gray 2001). Further, some of the key bycatch species (e.g. sparids) have been demonstrated to incur minimal damage and mortality associated with other methods of catching and discarding, such as recreational angling (Broadhurst et al. 1999, 2005).

Based on the logic above, our objectives here were to investigate the range of mortalities (partitioned into immediate and short-term, i.e. $<5$ d) of key teleosts discarded from prawn trawls and seines (in 2 estuaries) within the plausible limits of commercial treatments, mostly differentiated by extremes in the duration of gear deployment and the subsequent air exposure and sorting time of catches. In doing so, we aimed to assess the potential for mitigating unwanted fishing mortalities using a strategy of modified operational and/or post-capture handling procedures. 


\section{MATERIALS AND METHODS}

Equipment used and collection of control fish. Six experiments were done between February and May 2006 in Wallis Lake $\left(32^{\circ} 33^{\prime} \mathrm{S}, 152^{\circ} 51^{\prime} \mathrm{E}\right)$ and the Clarence River $\left(29^{\circ} 27^{\prime} \mathrm{S}, 153^{\circ} 09^{\prime} \mathrm{E}\right)$ using the following equipment: a chartered commercial prawn seiner (6 $\mathrm{m}$ in length) and trawler $(10 \mathrm{~m}) ; 4$ land-based $1000 \mathrm{l}$ polyethylene $(\mathrm{PE})$ holding tanks; up to 14 large $(1.5 \mathrm{~m}$ diameter $[\varnothing] \times 1.5 \mathrm{~m}$ depth $)$ and 90 small $(0.29 \mathrm{~m} \varnothing \times$ $0.42 \mathrm{~m}$ depth) cylindrical sea cages; and a dory $(4 \mathrm{~m})$ equipped with a fish-transport system. The holding tanks were located on the banks of each estuary and supplied with seawater at a maximum rate of $631 \mathrm{~min}^{-1}$ and aerated by air-stone diffusers. All sea cages were secured in the estuaries near the holding tanks. The large sea cages were only used in the Clarence River and were made of $22 \mathrm{~mm}$ knotless polyamide (PA) netting (with $1 \mathrm{~m}$ long zippers at the top), weighted by 2 stainless-steel rings and suspended from square frames of polyvinyl chloride (PVC) tubing $(100 \mathrm{~mm} \varnothing)$. Two clusters of 7 cages were anchored over depths between 2 and $2.5 \mathrm{~m}$. The small sea cages were made from modified $201 \mathrm{PVC}$ buckets with 1 top and 3 lateral 'windows' (each $<230 \mathrm{~cm}^{2}$ ) covered by $6 \mathrm{~mm}$ PVC mesh. The solid bases of the small sea cages were weighted with locally collected sediment to a depth of $6 \mathrm{~cm}$. Stainless steel clips were used to suspend the sea cages in 1 to $1.5 \mathrm{~m}$ of water along a rope stretched between steel stanchions secured to the bottom of both estuaries every 5 to $10 \mathrm{~m}$. The fish-transport system on the dory comprised up to ten $75 \mathrm{l} \mathrm{PVC}$ containers that were filled with water and aerated as above. The $75 \mathrm{l}$ containers were designed to fit 2 of the small sea cages. During transport, approximately $50 \%$ of the water in each 751 container was manually exchanged every 15 min.

At least $3 \mathrm{~d}$ prior to the start of each experiment, appropriate numbers and species of control fish were collected from the estuaries using cast nets, hook and line, beach seines and short deployments ( $<15 \mathrm{~min}$ ) of trawls and boat-based seines rigged with fine-meshed, knotless codends (see Broadhurst et al. 2004b, 2005 for details) and placed into the holding tanks. All control fish were handled, transported, fed and monitored for mortalities following the procedures outlined by Broadhurst et al. (1999).

Generic experimental protocol. In each of the 6 experiments, bycatches were subjected to the upper and lower limits of the most plausible range of existing commercial treatments (termed 'mild' and 'extreme'), mainly by varying the duration of the gear deployments and air exposure of the catch, which are 2 of the most common factors highlighted in a recent review as impacting the mortality of discards (Broadhurst et al. 2006b). The treatments were identified from previous observer-based studies (Liggins \& Kennelly 1996, Liggins et al. 1996, Gray 2001) and after discussions with local commercial fishers. Specifically, the mild treatments involved the shortest conventional deployments of the gears followed by the immediate sorting of catches in water-filled trays. Conversely, the extreme treatments comprised the longest conventional deployments, followed by sorting in dry trays. On the first day of each experiment, 4 consecutive gear deployments (alternating between mild and extreme treatments, i.e. 2 replicates of each) were done in areas known to contain large concentrations of bycatch. The key teleost species caught during these deployments were sampled for immediate and short-term mortalities and scale loss as follows.

For the assessment of immediate mortalities (termed the 'immediate-mortality groups'), bycatches were separated by species from the targeted prawns and, based on any perceived movement of the body and/or operculum, immediately classified as being alive or dead. All bycatch species in these 2 categories were eventually weighed and counted. Where catch volumes precluded absolute census onboard the fishing vessel, sub-samples were stored on ice and sorted the following day. Up to 5 live and dead specimens of key species were then selected from the 2 bycatch categories above (live individuals were euthanised in a solution of $100 \mathrm{mg} \mathrm{l}^{-1}$ benzocaine in seawater), individually placed into plastic bags and stored on ice for subsequent analyses of physical damage and scale loss in the laboratory (termed 'scale-loss group', see Table 1 and below for details).

To assess the short-term mortalities of live discards (termed the 'short-term mortality groups'), during each deployment samples of live individuals of the following species were randomly separated from the catch by hand: Gerres subfasciatus, Herklotsichthys castelnaui, Rhabdosargus sarba and Acanthopagrus australis (Table 1). Three live individuals of $R$. sarba and $G$. subfasciatus and $4 \mathrm{H}$. castelnaui were discarded into each of the small sea cages submersed in the waterfilled $75 \mathrm{l}$ containers onboard the dory (positioned alongside the fishing vessel). In contrast, owing to their larger sizes, A. australis were placed directly into the 751 containers (maximum of 20 fish container ${ }^{-1}$ ). All fish in the short-term mortality groups were then transported to the monitoring site within $40 \mathrm{~min}$ and transferred by either lifting the small sea cages from the dory and attaching them to the rope between the stanchions or, in the case of A. australis, lifting the 751 containers from the dory and placing them upside-down (so that fish could swim out) into the unzipped large sea cages. No fish were exposed to air during their transfer. 
Table 1. Total numbers of individuals of key teleost species collected for the assessment of scale loss and short-term mortalities from 2 replicate gear deployments for each treatment (mild and extreme) in each experiment with a prawn seiner and trawler at Wallis Lake and the Clarence River, respectively. For the short-term mortality group, matching numbers of controls were used unless indicated otherwise. Occupancy numbers sea cage ${ }^{-1}$ provided in parentheses. Mi: mild, Ex: extreme, -: not collected

\begin{tabular}{|c|c|c|c|c|c|c|c|c|c|c|c|c|}
\hline \multirow[b]{3}{*}{ Scale-loss group } & \multicolumn{8}{|c|}{ - Wallis Lake } & \multicolumn{4}{|c|}{ Clarence River - } \\
\hline & \multicolumn{2}{|c|}{ Expt 1} & \multicolumn{2}{|c|}{ Expt 2} & \multicolumn{2}{|c|}{ Expt 3} & \multicolumn{2}{|c|}{ Expt 4} & \multicolumn{2}{|c|}{ Expt 5} & \multicolumn{2}{|c|}{ Expt 6} \\
\hline & Mi & Ex & $\mathrm{Mi}$ & Ex & $\mathrm{Mi}$ & Ex & $\mathrm{Mi}$ & Ex & $\mathrm{Mi}$ & Ex & $\mathrm{Mi}$ & Ex \\
\hline Gerres subfasciatus & 20 & 20 & 20 & 20 & - & - & - & - & - & 20 & - & 20 \\
\hline Rhabdosargus sarba & - & - & - & - & - & 20 & - & 20 & - & - & - & - \\
\hline Acanthopagrus australis & - & - & - & - & - & - & - & - & - & 20 & - & 20 \\
\hline \multicolumn{13}{|l|}{ Short-term mortality group } \\
\hline Gerres subfasciatus & - & - & $60(3)$ & $60(3)$ & $30(3)$ & $30(3)$ & $30(3)$ & $30(3)$ & $60(3)$ & $60(3)$ & $60(3)$ & $60(3)$ \\
\hline Rhabdosargus sarba & - & - & $18(3)^{\mathrm{a}}$ & $18(3)^{a}$ & $60(3)$ & $60(3)$ & $60(3)$ & $60(3)$ & - & - & - & - \\
\hline Acanthopagrus australis & - & - & - & - & - & - & - & - & $80(20)$ & $80(20)$ & $36(9)$ & $36(9)$ \\
\hline Herklotsichthys castelnaui & - & - & - & - & - & - & - & - & - & - & $32(4)$ & $32(4)$ \\
\hline${ }^{\text {a No controls }}$ & & & & & & & & & & & & \\
\hline
\end{tabular}

Within $1 \mathrm{~h}$ of the last treatment of fish being transferred to the monitoring site, the water levels in the holding tanks (on the estuary bank) housing the same species were lowered to about 100 l. Using between 25 and $35 \mathrm{mg} \mathrm{l}^{-1}$ of benzocaine (ethyl-p-amino benzoate), fish were anaesthetised before appropriate numbers were randomly selected for use as controls (Table 1). The sedated control fish were scooped (in 5 l PVC buckets) and placed into the 751 containers on the dory before being transferred to the monitoring site as per the methodology described above for treatment fish. In most experiments, all caged fish were offered food (pellets or blood worms) daily.

Expts 1 to 4: prawn seining in Wallis Lake. Four of the 6 experiments (numbered 1 to 4 ) were done at night (between 21:00 and 02:00 h) in Wallis Lake using a prawn seiner between March and April 2006. The seine comprised knotted, PE netting throughout, attached to a $140 \mathrm{~m}$ head rope as described by Macbeth et al. (2005). During the mild treatment, a motored seiner deployed a marker buoy, an anterior wing, a codend and its 2 marker buoys and a posterior wing. The seiner returned to the first marker buoy via a semicircular route, towing the seine at a speed of $\sim 0.5 \mathrm{~m} \mathrm{~s} \mathrm{~s}^{-1}$ and pulling the wings together. After approximately $15 \mathrm{~min}$, the seiner stopped towing the seine and returned to the codend, which was lifted on board (using a rope attached to a float) and immediately placed into a $75 \mathrm{l}$ sorting container filled with lake water. For the extreme treatment, the gear was deployed as above, but instead of retrieving the codend after the first tow, a further 2 consecutive tows were done. This involved re-opening 1 of the wings after each tow (see Macbeth et al. 2005 for details). At the end of the third tow, the codend was retrieved and placed into a dry 751 sorting container.

All small sea cages (stocked with appropriate numbers of Gerres subfasciatus and Rhabdosargus sarba; see Table 1 for details) were transported (in the 751 containers onboard the dory) to the monitoring site within 10 min of fish being 'discarded'. During each experiment, the sea cages were monitored every $12 \mathrm{~h}$ over $3.5 \mathrm{~d}$.

Expts 5 and 6: prawn trawling in the Clarence River. Two experiments (Expts 5 and 6) were done during the day (between 07:00 and 15:00 h) between April and May 2006 using a commercial prawn trawler towing standard twin-rigged trawls attached to squaremesh codends (27 mm, PA mesh; see Broadhurst et al. 2004a for a detailed description of the gear and fishing method) in the Clarence River. The trawls were towed for 30 or $60 \mathrm{~min}$ and the catch sorted on a wet or dry 2001 tray in the mild and extreme treatments, respectively. For the mild treatment, a pump was used to continuously supply the tray with surface river water to a depth of up to $15 \mathrm{~cm}$. All fish in the shortterm mortality group, including matching numbers of control fish, were caged in appropriate numbers for all treatments (Table 1) and monitored every $24 \mathrm{~h}$ over $5 \mathrm{~d}$.

Data collected. The following categories of technical data were recorded during each gear deployment onboard the fishing vessels: the start and finish, towing speed and fishing depth of the deployment, the start and finish of gear retrieval once at the surface, and the subsequent time required to sort the catch. A Horiba U10 water quality meter was used to record 2 replicate readings of $\mathrm{pH}\left(-\log \mathrm{aH}^{+}\right)$, dissolved oxygen $\left(\mathrm{mg}^{-1}\right)$, water temperature $\left({ }^{\circ} \mathrm{C}\right)$, and salinity (PSU) at the surface of the estuary and in the $75 \mathrm{l}$ containers onboard the fish-transport dory. These water quality parameters were also collected daily as replicated readings at 2 different depths between the start and end points of the sea cage clusters at the monitoring sites. The air temperature and cloud cover were also recorded onboard the fishing vessel. 
Using the entire catches, the total number and weight of dead bycatch and the numbers of dead individuals of all abundant species were expressed as percentage mortalities deployment ${ }^{-1}$ (i.e. immediatemortality groups). For the scale-loss groups, physical damage to 'live' and 'dead' individuals was assessed as the total percentage scale loss using the general methods described by Main \& Sangster (1988) and Broadhurst et al. (1999), while deaths in the short-term mortality groups were expressed as the percentage in each cage, pooled across the monitoring period. Samples of live and dead fish from all 3 categories above were measured for total length (TL) to the nearest $0.5 \mathrm{~cm}$. At the end of each experiment, most of the surviving fish in the short-term mortality groups were released.

Statistical analyses. Data were analysed separately for each fishing method at each location. Balanced analyses of variance (ANOVA) were used to test the null hypothesis $\left(H_{0}\right)$ of no differences between treatments to selected species for the percentage of (1) immediate mortalities (in each deployment), (2) scale loss from live and dead individuals at the end of each deployment, and (3) short-term mortalities of live discards (after up to $5 \mathrm{~d}$, in each sea cage). Several hierarchical, nested and orthogonal models were used, comprising between 1 and 4 factors that included 'experiment number' (up to 4 levels), 'treatment of fish' (up to 3 levels: mild, extreme and control), 'deployment' (always 2 for each treatment of fish in each experiment) and 'status' (always alive or dead). Experiment number and deployment were considered random factors, while the treatment of fish and status were fixed. All factors were orthogonal except deployment, which was nested in the treatment of fish and experiment number. The different combinations of these factors and the specific models used are outlined in the 'Results' section.

Prior to all ANOVAs, data were tested for heterogeneity using Cochran's test and arcsine-root transformed where required. If homogeneity of variances could not be achieved, ANOVA was done at $\mathrm{p}=0.01$ to reduce the probability of a type I error. In all cases where there were missing replicates, these were replaced with the cell mean, and the residual degrees of freedom were adjusted accordingly. Appropriate interaction or nested terms that were non-significant at $p=0.25$ were pooled to increase power for the main factors of interest (i.e. treatment of fish and status). Significant $F$-ratios were investigated using a StudentNewman-Keuls (SNK) comparison of means test.

Where appropriate, the total (unpartitioned) estimates of discard mortality were calculated for the key species by combining their mean immediate and adjusted (for deaths to controls) short-term mortalities derived from the analyses above. For each gear type, the size-frequency distributions of key species sam- pled onboard the vessels (total catch) were combined across all deployments and experiments for each of the mild and extreme treatments and plotted. Where appropriate, the sizes of control individuals placed in the cages were similarly combined and plotted.

\section{RESULTS}

In a total of 24 gear deployments (6 experiments $\times$ 4 deployments), $0.5 \mathrm{t}$ of bycatches were caught, comprising 40 species (or groups) of teleosts (34 species), elasmobranchs (1), crustaceans (3) and other invertebrates (2). Gerres subfasciatus was the most abundant species, accounting for 74.77 and $37.05 \%$ of approximately 26500 and 10700 individuals caught during the experiments in Wallis Lake and the Clarence River, respectively. Other abundant commercially important species included Rhabdosargus sarba (4.32\% of the total catch) in Wallis Lake and Acanthopagrus australis (17.78\%) and Herklotsichthys castelnaui (11.16\%) in the Clarence River. The availability of these fish dictated the numbers that were used in the scale-loss and short-term mortality groups in each experiment (Table 1). The most abundant non-commercial species, including trumpeter Pelates quadrilineatus, fan-bellied leatherjacket Monacanthus chinensis, eastern frogfish Batrachomoeus dubius, pinkbreasted siphonfish Siphamia roseigaster and bullrout Notesthes robusta, were restricted to analyses of immediate mortalities only (see Tables 2 \& 3, Fig. 3e,f,k).

The mean water quality variables in the 751 containers collected at the fishing site onboard the fishtransport dory and at the monitoring sites (pooled across days) in each experiment were similar and were well within the natural tolerance limits of all fish monitored (Fig. 1). The only variable that showed a large difference was salinity, especially during Expts 5 and 6 in the Clarence River, with mean salinity levels ranging between 8.20 and 8.90 PSU at the fishing site and 24.80 and 26.20 PSU at the monitoring site (Fig. 1h).

\section{Expts 1 to 4: prawn seining in Wallis Lake}

The mild and extreme treatments were clearly separated by their mean $( \pm \mathrm{SE}$ ) duration of gear deployment $(12.88 \pm 2.73$ vs. $41.25 \pm 3.43 \mathrm{~min}$, respectively) and total bycatch $(1350 \pm 306$ vs. $1970 \pm 375$ ind.) and their air exposure $(1 \pm 0.00$ vs. $11.03 \pm 1.34 \mathrm{~min})$. In contrast, the sorting time was similar between treatments, taking $10.52 \pm 1.66$ and $10.28 \pm 1.52 \mathrm{~min}$, respectively. Mean $( \pm \mathrm{SE}$ ) air temperature and cloud cover across all deployments were $22.96 \pm 0.44^{\circ} \mathrm{C}$ and $58.67 \pm 11.33 \%$, respectively. Towing speed remained consistent in all deployments at approximately $0.5 \mathrm{~m} \mathrm{~s}^{-1}$. 

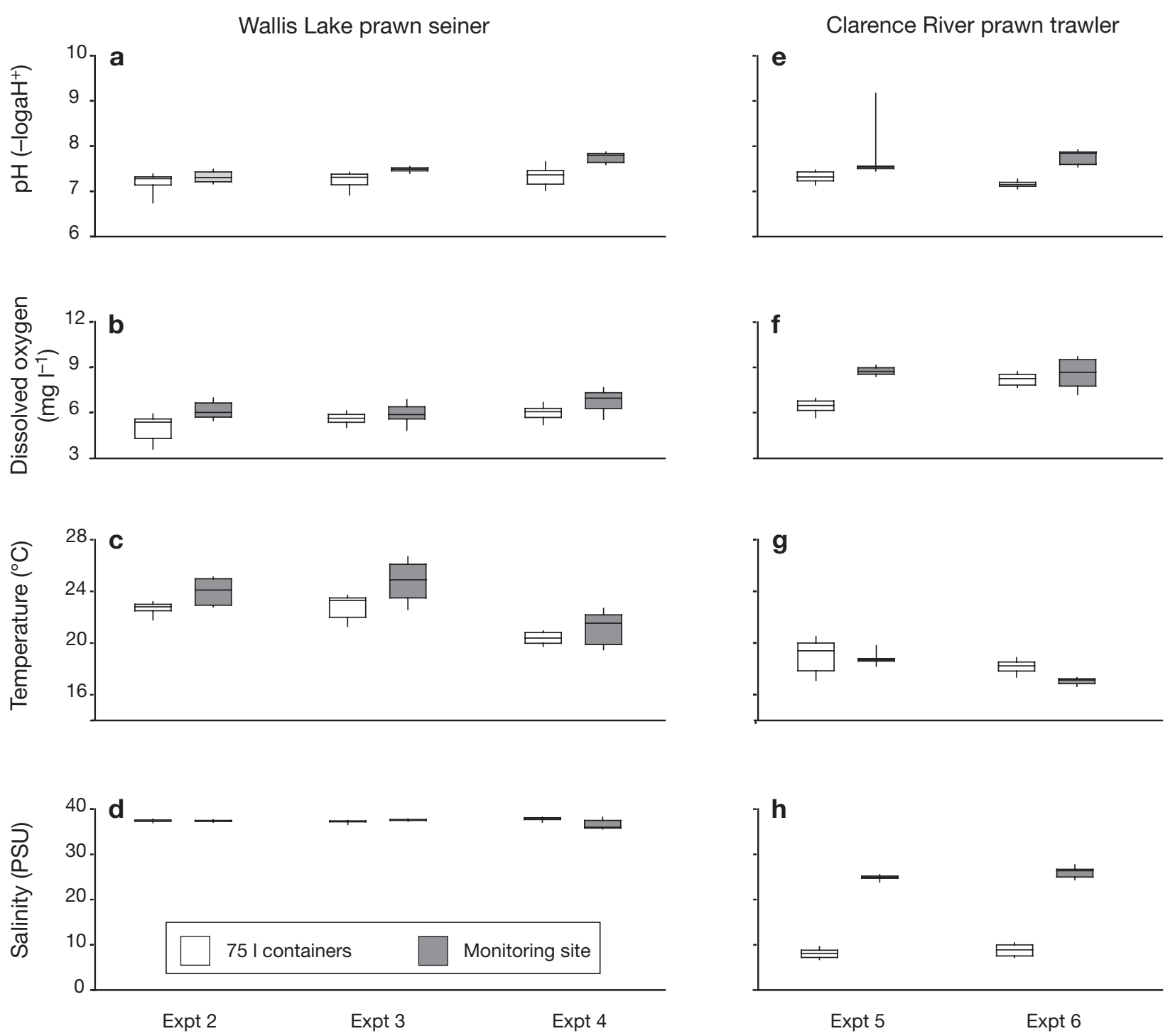

Fig. 1. $(\mathrm{a}, \mathrm{e}) \mathrm{pH},(\mathrm{b}, \mathrm{f})$ dissolved oxygen, $(\mathrm{c}, \mathrm{g})$ temperature and $(\mathrm{d}, \mathrm{h})$ salinity readings between the 10 th and 90 th percentile in $75 \mathrm{l}$ containers (white) used on the fish-transport dory and at the monitoring sites (grey). Line in middle is median

Gerres subfasciatus and Rhabdosargus sarba were caught in sufficient numbers for the assessment of scale loss and short-term mortality (Table 1). Irrespective of the species, all individuals were less than $30 \mathrm{~cm}$ TL, with similar size distributions among treatments (Fig. 2a,b).

\section{Immediate mortalities of total catch}

The percentage immediate mortality deployment ${ }^{-1}$ for the number and weight of total catch and numbers of Gerres subfasciatus, Rhabdosargus sarba, Pelates quadrilineatus, Monacanthus chinensis and Batrachomoeus dubius were analysed using a 2-factor (experiment and treatment of fish) ANOVA (Table 2). The interaction term was non-significant for all variables. Significant $F$-ratios were detected for the main effect of treatment of fish for the number and weight of total catch and the numbers of G. subfasciatus, R. sarba and $P$. quadrilineatus (Table 2). For all variables, the mean percentages of immediate mortalities deployment ${ }^{-1}$ were significantly greater in the extreme (between 35.50 and $86.13 \%$ ) than in the mild (5.50 and $47.63 \%$ ) treatments (Table 2, Fig. 3a-e). The main effect of experiment also returned significant $F$-ratios for the numbers of $R$. sarba, M. chinensis and B. dubius, with SNK tests revealing that significantly more $R$. sarba and B. dubius died during Expt 2 than in Expts 3 and 4 (Table 2). No definitive differences among experiments were detected for $M$. chinensis (Table 2, Fig. 3f). 


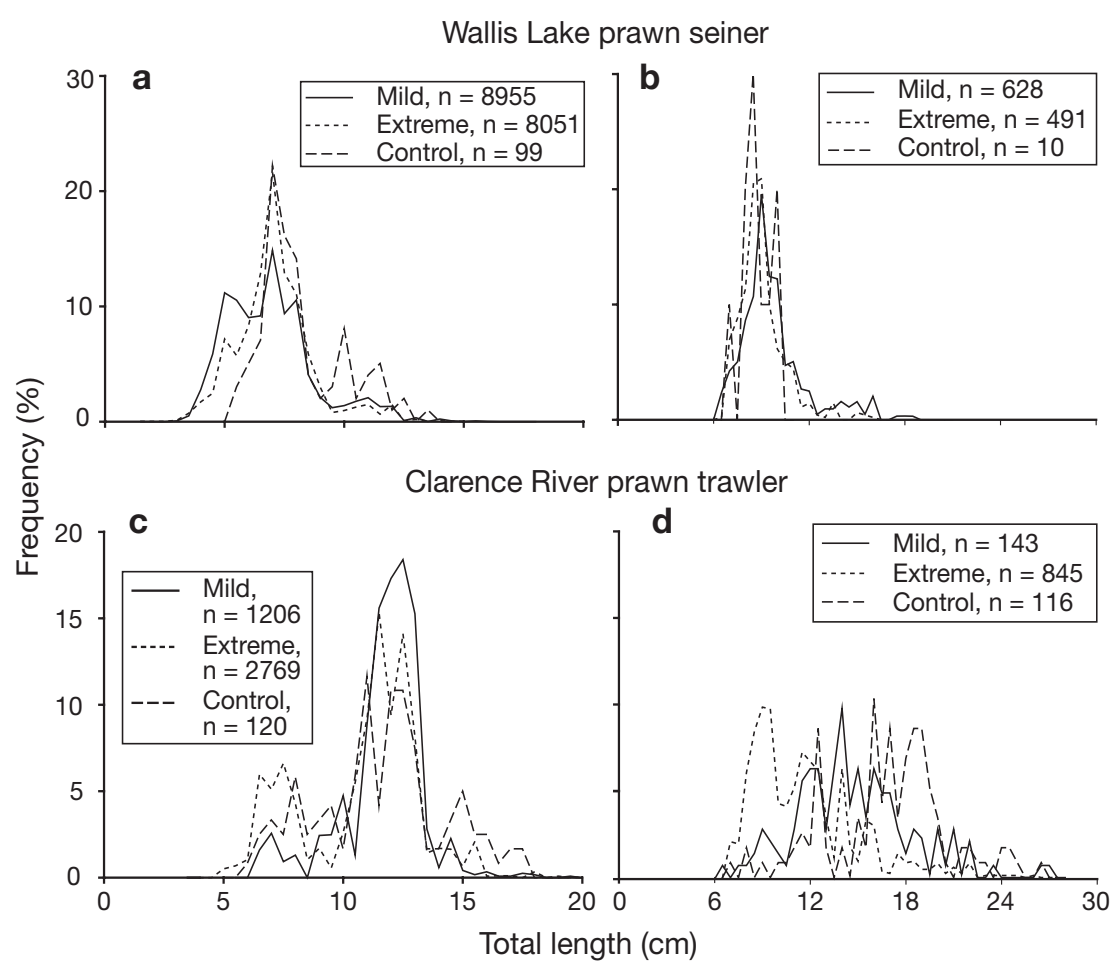

Fig. 2. Size-frequency distributions of (a) Gerres subfasciatus and (b) Rhabdosargus sarba from Wallis Lake and (c) G. subfasciatus and (d) Acanthopagrus australis from the Clarence River for the mild and extreme treatments and controls
Scale loss

Sufficient data were available for Gerres subfasciatus in the first 2 experiments to apply a 4 -factor model (comprising experiment, treatment of fish, deployment and status; Tables 1 \& 2). This returned a significant F-ratio only for the main effect of status (Table 2) and showed that live individuals had significantly less mean scale loss deployment $^{-1}(24.68 \pm 2.28 \%)$ than those that were dead $(33.53 \pm 2.19 \%)$ (Table 2 , Fig. 4a). Analyses of scale loss for Rhabdosargus sarba were limited to fish collected during the extreme treatments only, and a 3-factor model involving experiment, deployment and status was used (Tables 1 \& 2). Significant main effects of experiment and status were detected, with SNK tests revealing that all $R$. sarba lost significantly more scales in Expt $4(18.63 \pm 2.38 \%)$ than $3(10.65 \pm$ $2.23 \%)$, and also that dead fish (18.50 \pm $2.81 \%$ ) lost more scales than those that were alive $(10.78 \pm 1.68 \%$; Table 2 , Fig. 4b).

Table 2. Summary of balanced ANOVA models used to investigate the effects on percentage variables (all numbers except where indicated) and their significant terms (sig. terms), F-ratios and Student-Newman-Keuls (SNK) tests for Expts 1 to 4 done with a prawn seiner in Wallis Lake. Factors comprising the various models included 'experiment number' (up to 4; E), 'treatment of fish' (mild vs. extreme; T), 'deployment' (2 for each treatment of fish in each experiment; D) and 'status' (alive vs. dead; $\mathrm{S}$ ). ${ }^{* *} \mathrm{p}<0.01$; ${ }^{*} p<0.05$. 'pld': interaction or nested terms were non-significant at $p>0.25$ and the sums of squares pooled with the residual. Where this occurred, the revised degrees of freedom (df) are listed. $\left.<_{1}\right\rangle_{1}={ }_{1} \neq$, 'none': directions of differences detected in SNK tests

\begin{tabular}{|c|c|c|c|c|c|c|}
\hline Category and variable & Factors (levels) & Transform & Sig. terms & $F$-ratio & $\mathrm{df}$ & SNK differences \\
\hline \multicolumn{7}{|l|}{ Immediate mortality } \\
\hline Total catch & $\mathrm{E}(4)$ and $\mathrm{T}(2)$ & None & $\mathrm{T}$ & $25.13^{* *}$ & $1,11^{\text {pld }}$ & Mild < extreme \\
\hline Weight of total catch & $\mathrm{E}(4)$ and $\mathrm{T}(2)$ & None & $\mathrm{T}$ & $25.13^{* *}$ & $1,11^{\mathrm{pld}}$ & Mild < extreme \\
\hline Gerres subfasciatus & $\mathrm{E}(4)$ and $\mathrm{T}(2)$ & None & $\mathrm{T}$ & $11.19^{* *}$ & $1,11^{\text {pld }}$ & Mild $<$ extreme \\
\hline \multirow[t]{2}{*}{ Rhabdosargus sarba } & $\mathrm{E}(3)$ and $\mathrm{T}(2)$ & None & $\mathrm{E}$ & $7.15^{*}$ & $2,8^{\text {pld }}$ & $\mathrm{E} 2>\mathrm{E} 3=\mathrm{E} 4$ \\
\hline & & & $\mathrm{T}$ & $6.48^{*}$ & $1,8^{\text {pld }}$ & Mild < extreme \\
\hline Pelates quadrilineatus & $\mathrm{E}(3)$ and $\mathrm{T}(2)$ & None & $\mathrm{T}$ & $8.78^{*}$ & $1,8^{\text {pld }}$ & Mild < extreme \\
\hline Monacanthus chinensis & $\mathrm{E}(3)$ and $\mathrm{T}(2)$ & $\operatorname{Arcsine}(\sqrt{ }(x))$ & $\mathrm{E}$ & $5.05^{*}$ & $3,11^{\text {pld }}$ & None \\
\hline Batrachomoeus dubius & $\mathrm{E}(4)$ and $\mathrm{T}(2)$ & $\operatorname{Arcsine}(\sqrt{ }(x))$ & $\mathrm{E}$ & $16.76^{* *}$ & 3,8 & $\mathrm{E} 2>\mathrm{E} 1=\mathrm{E} 3=\mathrm{E} 4$ \\
\hline \multicolumn{7}{|l|}{ Scale loss } \\
\hline Gerres subfasciatus & $\mathrm{E}(2), \mathrm{T}(2), \mathrm{D}$ and $\mathrm{S}$ & None & $\mathrm{S}$ & $30.86^{* *}$ & $1,6^{\text {pld }}$ & Alive $<$ dead \\
\hline \multirow[t]{2}{*}{ Rhabdosargus sarba } & $\mathrm{E}(2), \mathrm{D}$ and $\mathrm{S}-$ all & None & $\mathrm{E}$ & $6.86^{*}$ & $1,37^{\text {pld }}$ & $\mathrm{E} 3<\mathrm{E} 4$ \\
\hline & extreme from E3 and 4 & & $\mathrm{~S}$ & $6.44^{*}$ & $1,37^{\text {pld }}$ & Alive $<$ dead \\
\hline \multicolumn{7}{|l|}{ Short-term mortality } \\
\hline Gerres subfasciatus & $100 \%$ mort. treat. ${ }^{-1}$ & & & & & \\
\hline \multirow[t]{2}{*}{ Rhabdosargus sarba } & $\mathrm{T}(2)$ and $\mathrm{D}-$ from E2 & None & $\mathrm{T}$ & 19.67 & 1,8 & Mild < extreme \\
\hline & $\begin{array}{l}\mathrm{E}(2), \mathrm{T}(2) \text { and } \mathrm{D}-\text { from } \\
\mathrm{E} 3 \text { and } 4\end{array}$ & None & $\mathrm{D}$ & $16.01^{* *}$ & 4,72 & $\begin{array}{l}\text { Mild } \neq \text { mild } \\
\text { extreme }=\text { extreme }\end{array}$ \\
\hline
\end{tabular}




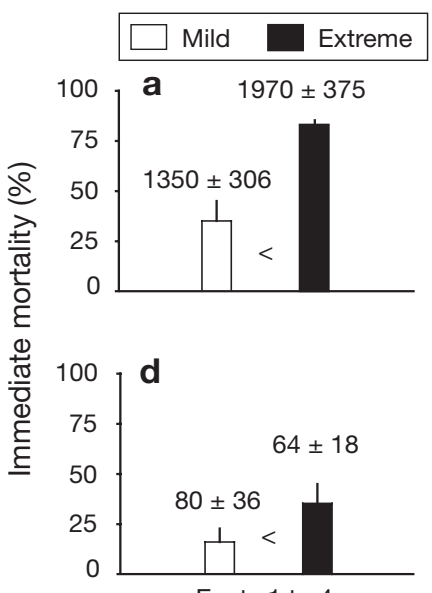

Wallis Lake prawn seiner
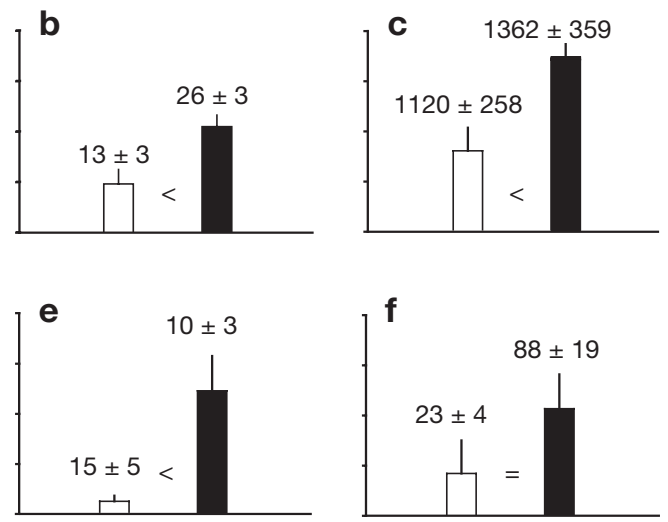

Expts 1 to 4

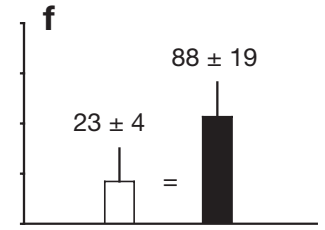

Expts 1 to 4

Clarence River prawn trawler
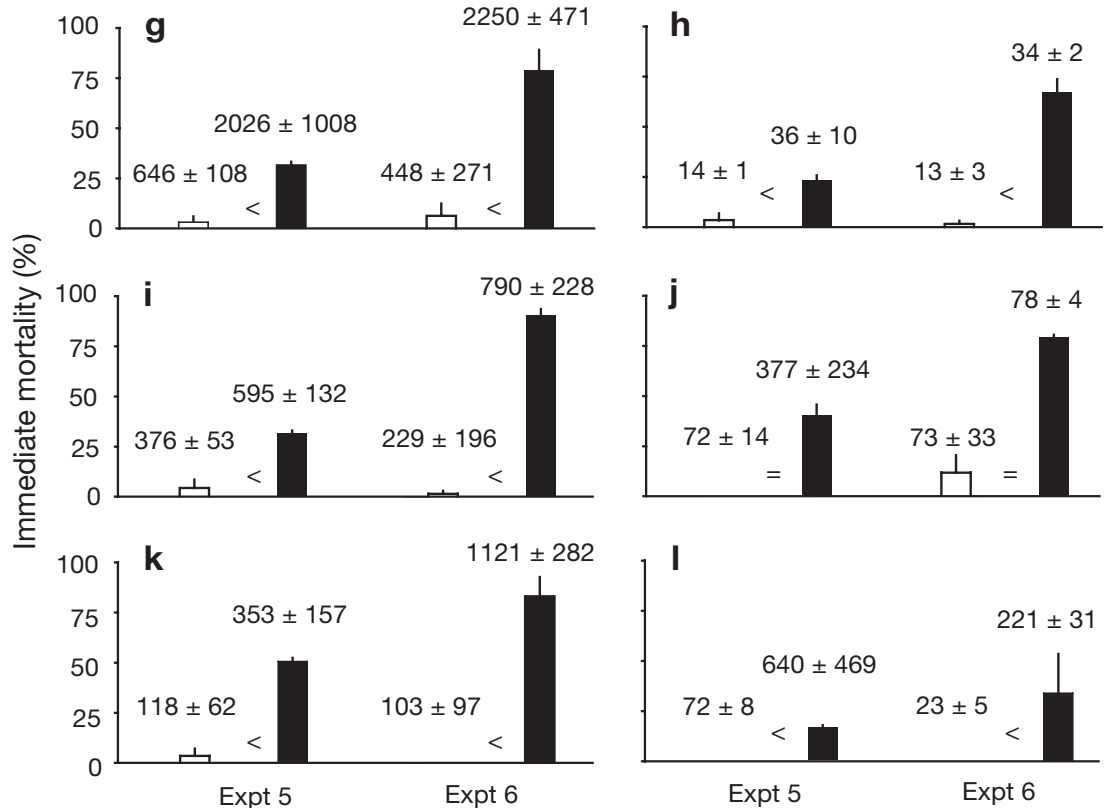

Fig. 3. Mean $(+\mathrm{SE})$ percentage immediate mortalities deployment ${ }^{-1}$ of the (a) number and (b) weight of the total catch, and numbers of (c) Gerres subfasciatus, (d) Rhabdosargus sarba, (e) Pelates quadrilineatus and (f) Monacanthus chinensis subjected to mild and extreme treatments by a prawn seiner in Wallis Lake and the $(\mathrm{g})$ number and $(\mathrm{h})$ weight of the total catch, and numbers of (i) G. subfasciatus, (j) Herklotsichthys castelnaui, (k), Siphamia roseigaster and (l) Acanthopagrus australis subjected to mild and extreme treatments by a prawn trawler in the Clarence River. Mean $(+\mathrm{SE})$ total numbers of fish deployment ${ }^{-1}$ are given above the histograms ciatus ( $\mathrm{n}=240$ ) from the mild and extreme treatments died in all experiments, precluding any formal analyses (Fig. 6a). The majority $(98 \%)$ of these mortalities occurred within $24 \mathrm{~h}$ of discarding (Fig. 5a-c). For R. sarba, 2 separate analyses were done. No controls were available for Expt 2 (Table 1), so a 2-factor ANOVA (treatment and deployment) was applied, which showed that a significantly greater percentage of $R$. sarba died sea cage ${ }^{-1}$ in the extreme $(94.50 \pm 5.5 \%)$ than in the mild $(16.67 \pm$ $11.42 \%$ ) treatments (Table 2, Fig. 6b). Control $R$. sarba were used in Expts 3 and 4 , but because none died (Fig. 5e,f), these were excluded from the analyses. A 3-factor (experiment, treatment of fish and deployment) ANOVA was applied to the data from the mild and extreme deployments, which detected significant differences among deployments. SNK tests of the appropriate means indicated a general trend of fewer short-term mortalities sea cage $^{-1}$ for the mild treatment (Table 2, Fig. 6c,d).

\section{Total mortalities of key species}

Using the means for the main effect of treatment of fish for the immediate and short-term mortalities to Gerres subfasciatus, the overall unpartitioned discard mortality estimates were calculated as 95.97 and $99.07 \%$ for the mild and extreme treatments, respectively. For Rhabdosargus sarba, the means from the main effect of treatment of fish for the immediate mortality groups were considered with those derived during the 2 analyses of short-term mortalities (Table 2) to provide ranges of 23.95 to $77.19 \%$ and 89.25 to $100 \%$ for the mild and extreme treatments, respectively.

\section{Short-term mortalities of live discards}

Short-term mortality estimates were made for Gerres subfasciatus and Rhabdosargus sarba in Expts 2 to 4 (Table 1). Of a total 120 control G. subfasciatus used across all 3 experiments, 8 died (all during Expt 2 and from 8 different cages), providing an overall mortality of $<6.67 \%$ (Fig. $5 \mathrm{a}-\mathrm{C}$ ). In contrast, all caged G. subfas-

\section{Expts 5 and 6: prawn trawling in the Clarence River}

As for the prawn seiner, the mild and extreme treatments onboard the trawler were well separated by differences in the duration of gear deployment (29.50 \pm 0.65 vs. $59.00 \pm 1.35 \mathrm{~min})$, total bycatches $(547 \pm 132.44$ vs. $2138.05 \pm 458.57$ ind.) and their air exposure (1.75 \pm 0.75 vs. $7.25 \pm 1.78 \mathrm{~min})$. Sorting times were similar 


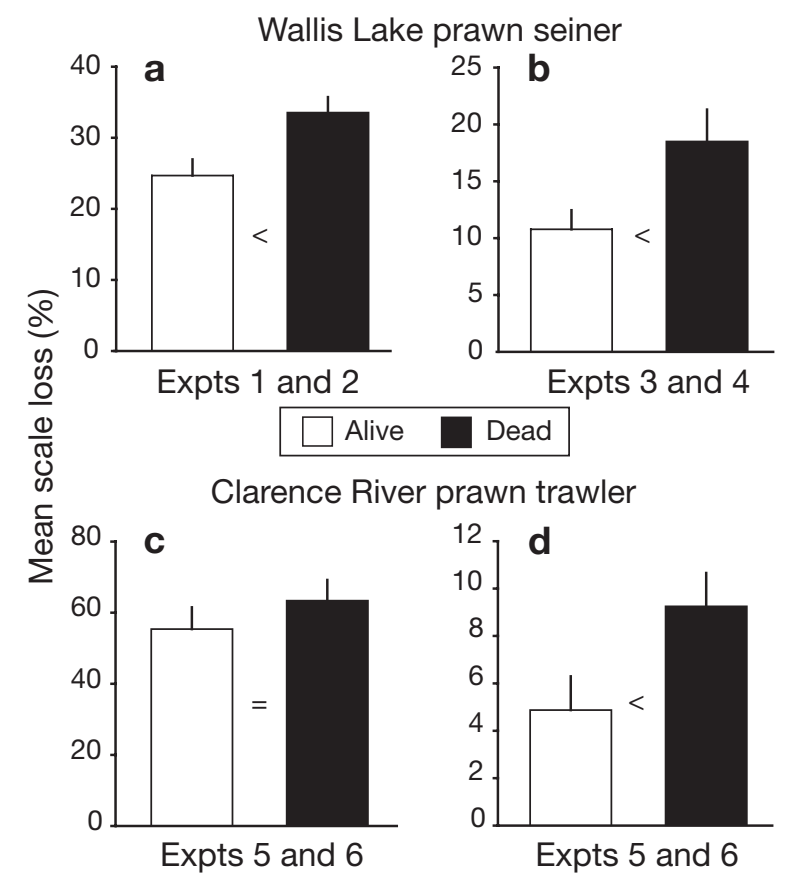

Fig. 4. Differences in mean $(+\mathrm{SE})$ percentage scale loss of (a) Gerres subfasciatus and (b) Rhabdosargus sarba caught by a prawn seiner in Wallis Lake, and (c) G. subfasciatus and (d) Acanthopagrus australis caught by a prawn trawler in the Clarence River between treatments $(5.25 \pm 0.85$ vs. $6.00 \pm 1.29 \mathrm{~min})$. The mean $( \pm \mathrm{SE})$ air temperature and cloud cover during fishing were $17.80 \pm 1.95^{\circ} \mathrm{C}$ and $15.00 \pm$ $3.66 \%$, respectively. Towing speed was approximately $1.2 \mathrm{~m} \mathrm{~s}^{-1}$ in all deployments.

All Gerres subfasciatus and Acanthopagrus australis were $\leq 20$ and $30 \mathrm{~cm} \mathrm{TL}$, respectively (Fig. 2c,d). No other size-frequency data were collected, although the other key species were all $\leq$ approximately $15 \mathrm{~cm}$ TL.

Immediate mortalities of total catch

A 2-factor (experiment and treatment of fish) ANOVA was used to analyse the percentage immediate mortality deployment ${ }^{-1}$ of all variables, except the number of Acanthopagrus australis (because no fish died in the mild treatment) and Notesthes robusta (no deaths in either treatment; Table 3, Fig. 31). The interaction term was significant for the number and weight of total catch and the numbers of Gerres subfasciatus and Siphamia roseigaster (Table 3). SNK tests of these differences revealed that in each experiment, significantly fewer fish died in the mild (0 to $6.39 \%$ ) than the extreme treatments (31.13 to $90.21 \%$; Table 3, Fig. $3 g-i, k)$. Significant main effects of experiment

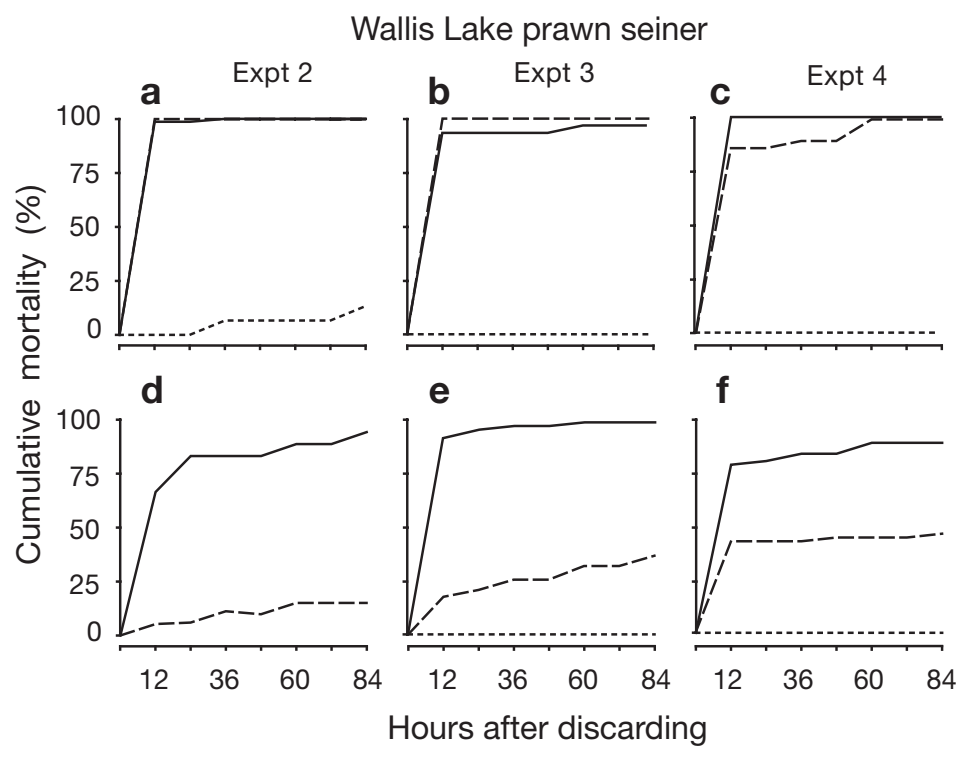

Fig. 5. Cumulative mortalities of $(\mathrm{a}-\mathrm{c})$ Gerres subfasciatus and (d-f) Rhabdosargus sarba in the short-term mortality groups collected during the mild and extreme gear deployments by a prawn seiner and their controls in Wallis Lake, and $(\mathrm{g}, \mathrm{h}) \mathrm{G}$. subfasciatus, $(\mathrm{i}, \mathrm{j})$ Acanthopagrus australis and (k) Herklotsichthys castelnaui for the same categories in the Clarence River

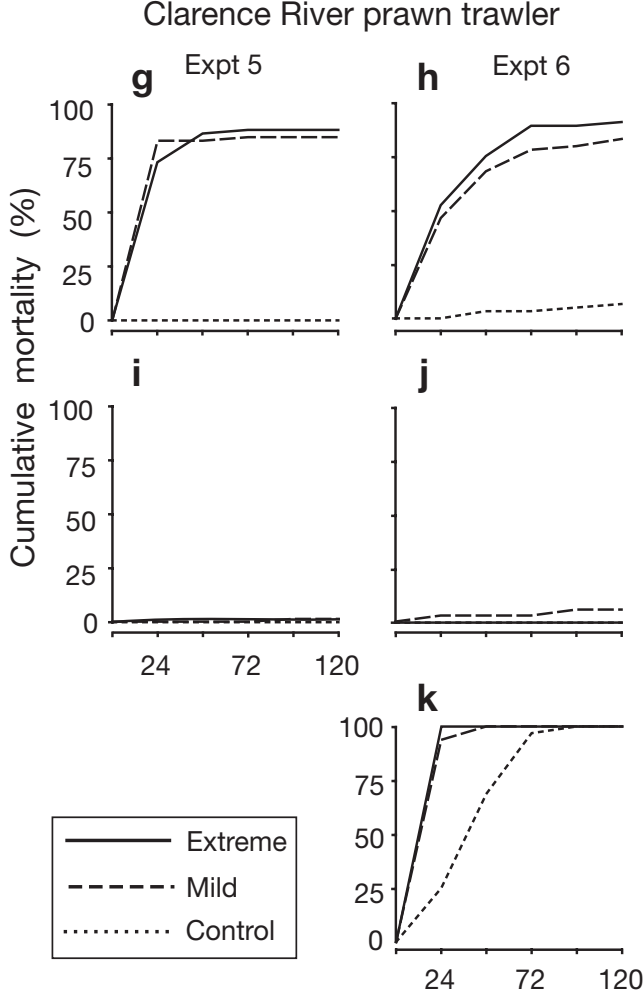

Hours after discarding 


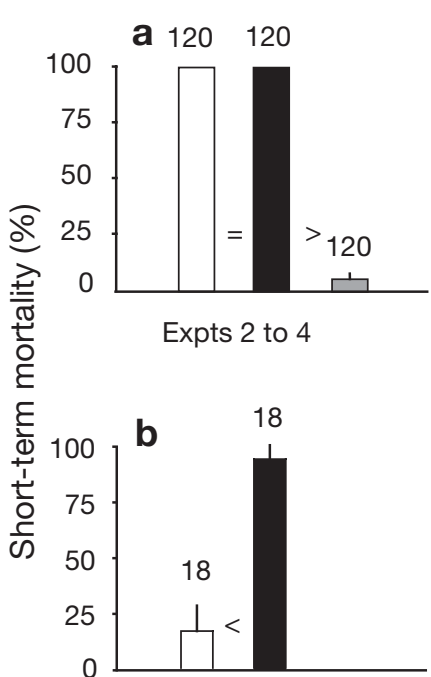

Expt 2
Wallis Lake prawn seiner

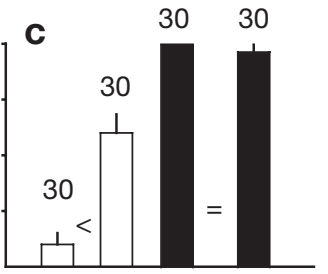

Expt 3
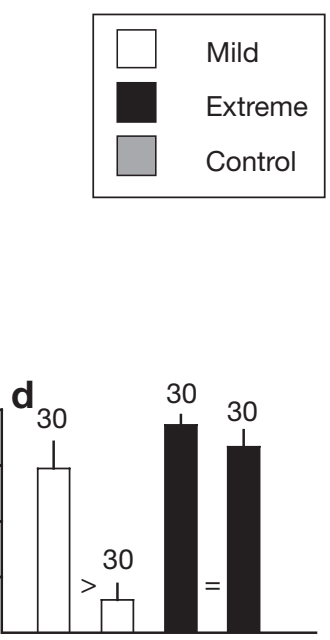

Expt 4
Clarence River prawn trawler
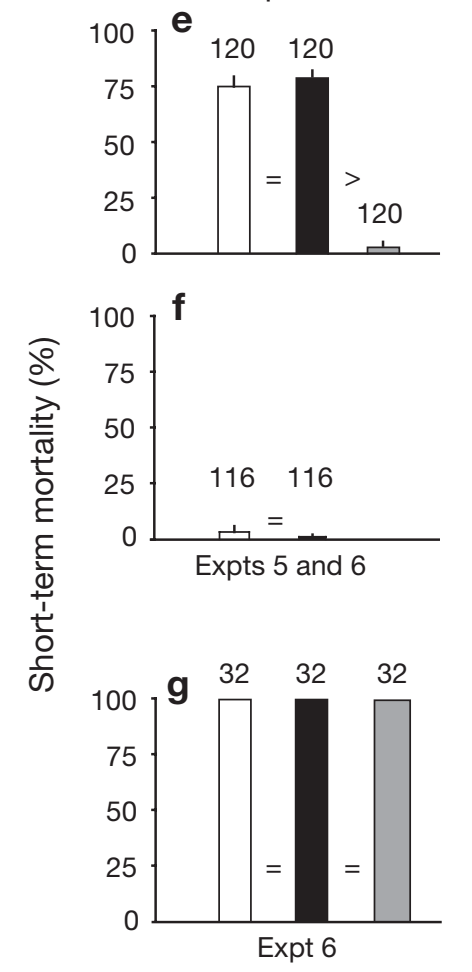

Fig. 6. Mean (+SE) percentage short-term mortalities deployment ${ }^{-1}$ of the numbers of (a) Gerres subfasciatus, (b-d) Rhabdosargus sarba (and controls, where collected) subjected to mild and extreme treatments by a prawn seiner in Wallis Lake and (e) $G$. subfasciatus, (f) Acanthopagrus australis and (g) Herklotsichthys castelnaui (and controls) subjected to mild and extreme treatments by a prawn trawler in the Clarence River. Total numbers of fish treatment ${ }^{-1}$ given above the histograms

Table 3. Summary of balanced ANOVA models used to investigate the effects on percentage variables (all numbers except where indicated) and their subsequent significant terms (sig. terms) tests, F-ratios and Student-Newman-Keuls (SNK) tests for Expts 5 and 6 done with a prawn trawler in the Clarence River. Factors comprising the various models included 'experiment number' (5 and $6 ;$ E), 'treatment of fish' (up to $3 ; \mathrm{T}$ ), 'deployment' (2 for each treatment of fish in each experiment; D) and 'status' (alive vs. dead; $S) .{ }^{* *} p<0.01,{ }^{*} p<0.05$. 'pld': interaction or nested terms were non-significant at $\mathrm{p}>0.25$ and the sums of squares pooled with the residual. Where this occurred, the revised degrees of freedom (df) are listed. $<_{1}>=$ : directions of differences detected in SNK tests

\begin{tabular}{|c|c|c|c|c|c|c|}
\hline Category and variable & Factors (levels) & Transform & Sig. terms & $F$-ratio & df & SNK differences \\
\hline \multicolumn{7}{|l|}{ Immediate mortality } \\
\hline Total catch & $\mathrm{E}$ and $\mathrm{T}(2)$ & None & $\mathrm{E} \times \mathrm{T}$ & $12.45^{*}$ & $1,4 \mathrm{~N}$ & Mild < extreme in E5 and E6 \\
\hline Weight of total catch & $\mathrm{E}$ and $\mathrm{T}(2)$ & None & $\mathrm{E} \times \mathrm{T}$ & $32.36^{* *}$ & $1,4 \mathrm{~N}$ & Mild < extreme in E5 and E6 \\
\hline Gerres subfasciatus & $\mathrm{E}$ and $\mathrm{T}(2)$ & None & $\mathrm{E} \times \mathrm{T}$ & $115.59^{* *}$ & $1,4 \mathrm{~N}$ & Mild < extreme in E5 and E6 \\
\hline Acanthopagrus australis & $\begin{array}{l}\text { No deaths in } \\
\text { mild treatment }\end{array}$ & & & & & \\
\hline Herklotsichthys castelnaui & $\mathrm{E}$ and $\mathrm{T}(2)$ & None & $\mathrm{E}$ & $24.24^{* *}$ & 1,4 & $\mathrm{E} 5<\mathrm{E} 6$ \\
\hline Siphamia roseigaster & $\mathrm{E}$ and $\mathrm{T}(2)$ & None & $\mathrm{E} \times \mathrm{T}$ & $11.89^{*}$ & $1,5^{\text {pld }}$ & Mild < extreme \\
\hline Notesthes robusta & $\begin{array}{l}\text { No deaths in } \\
\text { either treatment }\end{array}$ & & & & & \\
\hline \multicolumn{7}{|l|}{ Scale loss } \\
\hline Gerres subfasciatus & $\begin{array}{l}\text { E, D and S - } \\
\text { for extreme } \\
\text { treatment only }\end{array}$ & None & None & & & \\
\hline Acanthopagrus australis & $\begin{array}{l}\mathrm{E}, \mathrm{D} \text { and } \mathrm{S}- \\
\text { for extreme } \\
\text { treatment only }\end{array}$ & None & $\mathrm{S}$ & $4.83^{*}$ & $1,35^{\mathrm{pld}}$ & Alive $<$ dead \\
\hline \multicolumn{7}{|l|}{ Short-term mortality } \\
\hline Gerres subfasciatus & $\mathrm{E}, \mathrm{T}(3)$ and $\mathrm{D}$ & $\operatorname{Arcsine}(\sqrt{ }(x))$ & $\begin{array}{l}\mathrm{T} \\
\mathrm{D}\end{array}$ & $\begin{array}{r}367.92^{* *} \\
5.36^{* *}\end{array}$ & $\begin{array}{l}2,2 \\
6,108\end{array}$ & Mild $=$ extreme $>$ control \\
\hline Acanthopagrus australis & \multicolumn{6}{|c|}{$<3 \%$ mortality treatment ${ }^{-1}$} \\
\hline Herklotsichthys castelnaui & $100 \%$ mortality tre & ent $^{-1}$ & & & & \\
\hline
\end{tabular}


were detected for the number of Herklotsichthys castelnaui, with fewer dying in Expt 5 (20.26 $\pm 11.89 \%)$ than Expt 6 (45.26 $\pm 20.01 \%$; Table 3$)$.

\section{Scale loss}

Sufficient numbers of live and dead Gerres subfasciatus and Acanthopagrus australis were available only for analyses of scale loss from the extreme gear deployments (Table 1). Therefore, a 3-factor (experiment, deployment and status) model was used to investigate their percentage scale loss deployment ${ }^{-1}$ (Table 3). No significant F-ratios were detected for $G$. subfasciatus (Table 3, Fig. 4c). A significant main effect of status was detected for A. australis, with live individuals sustaining considerably less mean percentage scale loss deployment ${ }^{-1}(5.05 \pm 1.44 \%)$ than dead $(9.50 \pm 1.40 \%$ ) individuals (Table 3, Fig. 4d).

Short-term mortalities of live discards

Short-term mortality estimates were made for Gerres subfasciatus, Acanthopagrus australis and Herklotsichthys castelnaui. Most of the treatment G. subfasciatus died within 24 to $36 \mathrm{~h}$ after discarding (Fig. 5g,h). A 3-factor (experiment, treatment of fish and deployment) ANOVA was done for G. subfasciatus, and because 4 control fish $(n=120)$ had died, this group was included as a level in the treatment of fish. These analyses returned significant $F$-ratios for the latter 2 factors, with appropriate SNK tests revealing similar percentage mortalities sea cage ${ }^{-1}$ in the mild $(74.83 \pm 3.25 \%)$ and extreme $(79.42 \pm 2.59 \%)$ treatments, which were significantly greater than those in the control group (3.53 \pm $1.69 \%$; Table 3, Fig. 6e). No ANOVA was done on $A$. australis and $H$. castelnaui, since $<3$ and $100 \%$, respectively, died in each treatment (Table 3, Figs. 5i-k \& 6f,g).

\section{Total mortalities of key species}

The means of immediate mortalities for the interaction between treatment of fish and experiment for Gerres subfasciatus were combined with those from the short-term mortalities for the main effect of treatment of fish and used to estimate total mortalities between 71.74 and $72.50 \%$ and between 83.40 and $97.64 \%$ for the mild and extreme treatments, respectively. The same groups of means were used to estimate total mortalities to Acanthopagrus australis of $3.40 \%$ for the mild treatment and between 17.60 and $35.01 \%$ for the extreme treatment. All treatment and control Herklotsichthys castelnaui died.

\section{DISCUSSION}

This study has provided the first published estimates of the short-term fate of teleosts discarded from prawn fisheries in southeastern Australia and, in doing so, has revealed considerable species-specific variability in damage and mortality, most of which can be attributed to the main effects or interactions between previously established dominant technical, environmental and biological factors (Davis 2002, Broadhurst et al. 2006b). By examining 2 general categories of treatments designed to represent the range of severity of conventional operations, and through partitioning mortality into that which occurred (1) during the gear deployments and (2) after subsequent handling and discarding, we have also provided information on the potential for simple changes to operational and/or handling procedures to improve the survival of key discards.

While the observed results are spatially and temporally restricted to the treatments examined, and therefore should not be extrapolated to provide quantitative assessments of the impacts of discarding across all fleets and fisheries in NSW estuaries, they are nevertheless indicative of some of the short-term effects on discards associated with conventional practices and support the general literature on this topic. In particular, by combining the partitioned estimates of mortality, it is apparent that like many similarly handled small teleosts discarded from active gears worldwide (Broadhurst et al. 2006a), the majority (between 72 and $100 \%$ ) of Gerres subfasciatus and Herklotsichthys castelnaui died after discarding, mostly within 24 to 48 h. In comparison, the total discard mortalities of trawled Acanthopagrus australis and seined Rhabdosargus sarba generally were more protracted (over up to $120 \mathrm{~h}$ ) and ranged from 3 to $35 \%$ and from 24 to $100 \%$, respectively. For $A$. australis, the percentages dying were comparable to those recorded for individuals released from capture by hook and line (e.g. between 8 and $28 \%$; Broadhurst et al. 2005), while $R$. sarba incurred a similar range of fatalities as another local sparid (snapper Pagrus auratus) discarded during trawling (between 30 and 100\%, Wassenberg \& Hill 1993, Sumpton \& Jackson 2005).

The species-specific variation among total (unpartitioned) mortalities was reflected in the partitioned estimates (especially immediate mortality) and can be attributed to individual tolerances to the 3 main factors used to delineate the treatments, including (1) the duration of gear deployment, (2) catch volume, and (3) air exposure during sorting. The influences of these factors can be further separated and discussed according to the partitioned mortalities, with (1) and (2) directly responsible for the differences among immediate deaths, while (3) had a cumulative impact on the fate of live discards. 
The effects of deployment duration and/or catch volume (1 and 2 above) on immediate mortality were clearly illustrated by the significant differences between treatments for both gears. More specifically, compared to the mild seining treatment, between over 1.5 and 11 times more Gerres subfasciatus, Rhabdosargus sarba and Pelates quadrilineatus were observed dead after being subjected to the extreme seining treatment (Table 2, Fig. 3). Similarly, while there were comparatively fewer significant differences among immediate mortalities onboard the trawler, the above trend remained the same for all species, with considerably more deaths during the extreme trawling treatment (Table 3, Fig. 3). These proportionally greater immediate mortalities during the longer deployments can be explained with respect to mechanical interactions during the capture process. Previous studies have shown that when fish initially detect a towed trawl or seine, they attempt to orientate away, and, depending on their swimming ability (dictated by factors such as size, water temperature and physiology; e.g. Beamish 1978), either escape or are progressively herded back towards the codend (Wardle 1983). Once in the narrow confines of the codend, swimming fish crowd together, become disorientated and repeatedly collide with each other and the meshes (Watson 1989). Depending on specifies-specific endurances, swimming individuals eventually fatigue and are impinged against the codend meshes or the build-up of catch. In addition to exhaustion, this process causes a range of abrasion and/or compression injuries and subsequent mortalities that are typically positively correlated with the duration of deployment and/or the volume of the catch, and often aggravated by the composition of the latter (Berghahn et al. 1992, Colura \& Bumguardner 2001).

The extent to which individuals of a particular species are able to tolerate the stressors evoked during capture in active gears depends on several biological characteristics, but particularly their physical resilience (Davis 2002). Our data support this trend, with the greatest magnitudes of differences in immediate mortalities between treatments for soft-bodied species like Gerres subfasciatus and Siphamia roseigaster. For G. subfasciatus, their fragility translated to a mean scale loss between 25 and $60 \%$, which was correlated with mortality for the discarded seined individuals. In contrast, while seined Rhabdosargus sarba and trawled Acanthopagrus australis demonstrated a similar relationship between damage and mortality, their overall scale loss was considerably lower, with means between 11 and $19 \%$ and between 5 and $10 \%$, respectively, for live and dead individuals (Fig. 4). This damage is comparable to that observed by Broadhurst et al. (1999) for live A. australis (<5\% scale loss) that escaped through the guiding panel of a Nordmøre-grid after simulated trawling and supports the general resilience of this species to withstand interactions with fishing gears (Broadhurst et al. 2005).

In addition to the impacts on fish caused during the deployment and retrieval of the gears, the subsequent sorting and handling would have evoked cumulative negative effects on those discarded alive individuals, which for Gerres subfasciatus, Herklotsichthys castelnaui and Acanthopagrus australis further reflected their relative robustness. For example, unlike A. australis, which incurred short-term mortalities of $<3 \%$, the majority (between 83 and 100\%) of live G. subfasciatus and $H$. castelnaui died soon after discarding. While all controls for the latter species also died (this species is very fragile and all controls were in poor condition due to their initial capture), there were few deaths in any of the other control groups, suggesting that the treatments (and not the experimental design) were responsible for the observed mortalities. In support of this assumption, the environmental parameters at the monitoring sites were all well within the ranges tolerated by the monitored species.

As well as a general concordance between overall resilience and short-term mortality, there were no significant differences between the mild and extreme treatments for these partitioned estimates, indicating that (1) the catching mechanisms had a dominant impact on Gerres subfasciatus and Herklotsichthys castelnaui that ultimately caused their mortality, regardless of the different amounts of air exposure during handling; and (2) Acanthopagrus australis were able to tolerate exposure to air within the times examined (approximately $7 \mathrm{~min}$ ). Unlike trawled $A$. australis, the seined Rhabdosargus sarba incurred significantly fewer short-term mortalities during the mild treatment. However, in addition to inherent speciesspecific variability, this difference may reflect the relatively longer air exposure of $R$. sarba during the extreme treatment onboard the seiner (i.e. $11 \mathrm{vs} .7 \mathrm{~min}$ for $A$. australis onboard the trawler) and/or their much smaller sizes (Fig. 2). Further work is required to validate the potential for these effects for R. sarba, and also to investigate their variability in short-term survival during the mild treatments.

Irrespective of the species-specific differences in short-term mortalities, the overwhelming trend of significant reductions in immediate mortalities for most species during the mild treatments indicates that limiting the duration of the gear deployments could have considerable utility in mitigating total discard mortalities. Although shorter gear deployments would reduce effort in terms of swept area (and therefore catches) this might be compensated for in trawls by an improved efficiency, since several previous studies have identified a negative correlation between catch per 
unit of effort and deployment duration (e.g. Gødo et al. 1990, Wassenberg et al. 1998). The exact mechanisms underlying this relationship remain unclear, although in some cases, relatively lower catches and subsequent drag during shorter deployments may transcend to a better maintenance of trawl geometry (Wassenberg et al. 1998). One advantage of short gear deployments is that, in some cases, they allow fishers to more accurately determine areas of high abundances of prawns and bycatch, and therefore maximise their fishing operation.

While there were few apparent benefits of sorting in water in terms of reducing the short-term mortality of Gerres subfasciatus, Herklotsichthys castelnaui and Acanthopagrus australis, given the observations for Rhabdosargus sarba, this practice may still be appropriate when individuals are likely to be exposed to air for long periods. Further, it is important to consider that the influences of the treatments examined in this study were limited to the assessments of immediate and short-term mortalities of discards and did not extend to other impacts, such as a reduced ability to evade predation or infection arising from physical and physiological disturbances. Intuitively, a combination of simple operational and/or post-capture handling procedures that mitigate all potentially negative impacts on the health of discards would ultimately benefit their survival. Used in combination with modifications designed to improve size and species selectivity, such a strategy could help address some of the remaining negative impacts associated with bycatches and discarding.

Acknowledgements. This study was funded by the NSW Department of Primary Industries (DPI) and the Australian Fisheries Research and Development Corporation (Grant no. 2005/056), and approved by the NSW DPI Animal Care and Ethics Committee (ACEC REF 05/10). The work would not have been possible without the assistance of the Cheers and Johnson families and C. Brand, A. Hulme, S. McGrath and P. Butcher.

\section{LITERATURE CITED}

Andrew NL, Pepperell JG (1992) The by-catch of shrimp trawl fisheries. Oceanogr Mar Biol Annu Rev 30:527-565

Beamish FWH (1978) Swimming capacity. In: Hoar WS, Randall DJ (eds) Fish physiology, Vol VII. Locomotion. Academic Press, New York, p 101-187

Berghahn R, Waltemath M, Rijnsdorp AD (1992) Mortality of fish from the by-catch of shrimp vessels in the North Sea. J Appl Ichthyol 8:293-306

Blaber SJM, Cyrus DP, Albaret JJ, Ching CV and 7 others (2000) Effects of fishing on the structure and functioning of estuarine and nearshore ecosystems. ICES J Mar Sci 57: 590-602

Broadhurst MK (2000) Modifications to reduce bycatch in prawn trawls: a review and framework for development. Rev Fish Biol Fish 10:27-60
Broadhurst MK, Kennelly SJ (1995) A trouser-trawl experiment to assess codends that exclude juvenile mulloway (Argyrosomus hololepidotus) in the Hawkesbury River prawn-trawl fishery. Mar Freshw Res 46:953-958

Broadhurst MK, Kennelly SJ (1996) Rigid and flexible separator panels in trawls that reduce the by-catch of small fish in the Clarence River prawn-trawl fishery, Australia. Mar Freshw Res 47:991-998

Broadhurst MK, Kennelly SJ, Isaksen B (1996) Assessments of modified codends that reduce the by-catch of fish in two estuarine prawn-trawl fisheries in New South Wales. Fish Res 27:89-111

Broadhurst MK, Barker DT, Kennelly SJ (1999) Scale-loss and survival of juvenile yellowfin bream, Acanthopagrus australis, after simulated escape from a Nordmøre-grid guiding panel and release from capture by hook and line. Bull Mar Sci 64:255-268

Broadhurst MK, Millar RB, Kennelly SJ, Macbeth WG, Young DJ, Gray CA (2004a) Selectivity of conventional diamondand novel square-mesh codends in an Australian estuarine penaeid-trawl fishery. Fish Res 67:183-194

Broadhurst MK, Millar RB, Young DJ, Wooden MEL, Rowland S (2004b) Atypical size selection of captive school prawns, Metapenaeus macleayi, by 3 recreational fishing gears in south-eastern Australia. NZ J Mar Freshw Res 38: 755-766

Broadhurst MK, Gray CA, Reid DD, Wooden MEL, Young DJ, Haddy JA, Damiano C (2005) Mortality of key fish species released by recreational anglers in an Australian estuary. J Exp Mar Biol Ecol 321:171-179

Broadhurst MK, Dijkstra KKP, Reid DD, Gray CA (2006a) Utility of morphological data for key species in southeastern Australian beach-seine and otter-trawl fisheries: predicting mesh size and configuration. NZ J Mar Freshw Res 40:259-272

Broadhurst MK, Suuronen P, Hulme A (2006b) Estimating collateral mortality from towed fishing gear. Fish Fish (Oxf) 7:180-218

Colura RL, Bumguardner BW (2001) Effect of the salt-box catch-bycatch separation procedure, as used by the Texas shrimp industry on short-term survival of bycatch. Fish Bull 99:399-409

Davis MW (2002) Key principles for understanding fish bycatch discard mortality. Can J Fish Aquat Sci 59: 1834-1843

Dunning DJ, Ross QE, Mattson MT, Geoghegan P, Waldman JR (1989) Reducing mortality of striped bass captured in seines and trawls. N Am J Fish Manag 9:171-176

Gødo OR, Pennington M, Vølstad JH (1990) Effect of tow duration on length composition of trawl catches. Fish Res 9:165-179

Gray CA (2001) Spatial variation in by-catch from a prawn seine-net fishery in a south-east Australian coastal lagoon. Mar Freshw Res 52:987-993

Kelleher K (2005) Discards in the world's marine fisheries: an update. FAO Fish Tech Pap 470:1-131

Liggins GW, Kennelly SJ (1996) By-catch from prawn trawling in the Clarence River estuary, New South Wales, Australia. Fish Res 58:95-107

Liggins GW, Kennelly SJ, Broadhurst MK (1996) Observerbased survey of by-catch from prawn trawling in Botany Bay and Port Jackson, New South Wales. Mar Freshw Res 47:877-888

Macbeth WG, Broadhurst MK, Millar RB, Smith SDA (2005) Increasing codend mesh openings: an appropriate strategy for improving the selectivity of penaeid fishing gears in an Australian estuary? Mar Freshw Res 56:889-900 
Macbeth WG, Broadhurst MK, Paterson BD, Wooden MEL (2006) Reducing the short-term mortality of juvenile school prawns (Metapenaeus macleayi) discarded during trawling. ICES J Mar Sci 63:831-839

Main J, Sangster GI (1988) Scale damage and survival of young gadoid fish escaping from the cod-end of a demersal trawl. In: DeAlteris JT (ed) Proceedings of a gear selectivity and survivability workshop. University of Rhode Island Sea Grant Advisory Service, Narragansett, RI, p 17-33

Pauly D, Christensen V, Guenette S, Pitcher TJ, Sumaila UR, Walters CJ, Watson R, Zeller D (2002) Towards sustainability in world fisheries. Nature 418:689-695

Sumpton W, Jackson S (2005) The effects of incidental trawl capture of juvenile snapper (Pagrus auratus) on yield of a sub-tropical line fishery in Australia: an assessment examining habitat preferences and early life history character-

Editorial responsibility: Anne Berit Skiftesvik, Storebø, Norway istics. Fish Res 71:335-347

Wardle CS (1983) Fish reactions to towed fishing gears. In: McDonald AG, Priede IG (eds) Experimental biology at sea. Academic Press, New York, p 167-195

Wassenberg TJ, Hill BJ (1993) Selection of the appropriate duration of experiments to measure the survival of animals discarded from trawlers. Fish Res 17:343-352

Wassenberg TJ, Burridge CY, Connell M, Gribble N (1998) A validation of short-duration scientific tows as a representation of long commercial-length tows: comparing the catch rates, sizes composition and species composition of prawn trawler bycatch in the far northern Great Barrier Reef, Australia. Fish Res 36:35-46

Watson J (1989) Fish behaviour and trawl design: potential for selective trawl development. In: Campell CM (ed) Proceedings of the world symposium on fishing gear and fishing vessels. Marine Institute, St. John's, p 25-29

Submitted: February 19, 2007; Accepted: April 26, 2007 Proofs received from author(s): June 22, 2007 